\section{LA NEGACIÓN DEL PASADO DE LOS «OTROS»: ARQUEOLOGÍA Y XENOFOBIA}

\author{
THE DENIAL OF THE PAST OF OTHERS: \\ ARCHAEOLOGY AND XENOPHOBIA
}

\author{
ANA M. ${ }^{a}$ MANSILLA CASTAÑO $(*)$
}

Dedicado a Ahoua Raymond; amante del pasado y de sus gentes.

\section{RESUMEN}

Este artículo ofrece un acercamiento al estado de la cuestión de un tema poco tenido en cuenta hasta hace poco en la práctica arqueológica. Se hace referencia a una serie de casos procedentes de distintos contextos geográficos y temporales (Gran Zimbabwe, la Alemania nazi, los saamis, etc.) como muestra de la variedad de formas en que el sesgo xenófobo y racista se ha manifestado sobre la práctica arqueológica. Se presta especial atención a la situación actual de la Arqueología en Europa, no exenta de dificultades ante el surgimiento de movimientos nacionalistas, racistas, xenófobos y se plantea qué responsabilidad le corresponde al arqueólogo inmerso en esta realidad socio-política.

\begin{abstract}
This article approaches a topic little considered until recently in archaeological practice. It refers to a series of examples from different geographical and temporal contexts (Great Zimbabwe, Nazi Germany, the Saamis, etc.) as a sample of the variety of forms in which xenophobia and racism have affected archaeological practice. It points out the actual situation of Archaeology in Europe which is not free of difficulties in the face of the revival of nationalistic, xenophobic and racist movements. It questions the responsibility of the archaeologist submerged in this socio-political reality.
\end{abstract}

(*) Departamento de Prehistoria. Facultad de Geografía e Historia. Universidad Complutense de Madrid. 28040 Madrid. El artículo fue remitido en su versión final el 8-IV-97.
Palabras clave: Arqueología y política. Xenofobia. Nacionalismo. Racismo. Colonialismo. Gran Zimbabwe. Constructores de Túmulos. Saamis. Arqueología medieval. Arqueología islámica. Identidad europea. Educación. Difusión.

Key words: Archaeology and politics. Xenophobia. $\mathrm{Na}$ tionalism. Racism. Colonialism. Great Zimbabwe. Mound builders. Saamis. Medieval archaeology. Islamic archaeology. European identity. Education. Difussion.

\section{INTRODUCCIÓN: RACISMO EN LA ARQUEOLOGÍA EN EL CONTEXTO DE LA ARQUEOLOGÍA Y LA POLÍTICA (1)}

La existencia de racismo en la práctica arqueológica tenemos que abordarla dentro de un contexto más amplio como es el de la relación entre la política y la Arqueología. En un sentido tradicional el concepto de racismo hace referencia al «comportamiento, la opinión y la doctrina que tiende a justificar las diferencias culturales o sociales por diferencias biológicas permanentes y hereditarias» (Adam, 1984: 90); sin embargo hoy este concepto resulta unas veces sobredi-

(1) Este trabajo ha sido realizado durante la estancia (Febrero-Junio 1996) en el Departamento de Arqueología de la Universidad de Southampton (Inglaterra) como becaria del Programa Erasmus y se ha beneficiado de las enseñanzas y orientaciones de los profesores Julian Thomas y Thomas Dowson. 
mensionado y otras confuso, definiendo en ocasiones a toda fobia hacia el otro, mientras que comportamientos claramente racistas se remiten a la etnicidad concepto que empezó a generalizarse después de la Segunda Guerra Mundial por parecer más aséptico (Ventura i Oller, 1994: 131). Mi convicción personal en este trabajo es que la Arqueología no es una disciplina aislada y aséptica sino que está inmersa en un contexto socio-político determinado. En este sentido cuando las ideas racistas aparecen, la Arqueología se empapa de ellas. Un marco de referencia que puede resultarnos útil en la valoración del racismo para entender por qué se valora ahora es el desarrollo de las últimas tendencias de la Arqueología, que ponen su atención en aspectos de la realidad humana pasada y presente que antes habían pasado desapercibidas: la arqueología de las minorías, la del género, la Arqueología en relación con el patrimonio y su difusión...

La tónica a lo largo de la historia de la Arqueología, que se mantiene en el presente y que parece apuntar al futuro, ha sido una estrecha vinculación entre la Arqueología y la política. Esta conexión ha afectado a la sociedad de una manera amplia y diversa en el tiempo y el espacio, como veremos en los ejemplos, y su influencia se ha dejado sentir en los distintos aspectos de la Arqueología: en la selección del tipo de yacimiento a excavar, el tipo de estudios a realizar y el tipo de interpretaciones a difundir.

La Arqueología como disciplina ha ido desarrollándose en etapas en todas las zonas del globo donde se ha ejercido. Se han percibido los cambios que el paso de una a otra ha supuesto, si bien su inicio y duración han sido diferentes y han estado marcadas por la situación singular de cada zona (Trigger, 1989). Es útil hacer referencia a estas etapas, que vamos a presentar a grandes rasgos, pues en los distintos ejemplos que veremos más adelante se observará cómo ejercen influencia en las investigaciones. 1) Una primera etapa se corresponde con el inicio de la disciplina a finales del siglo pasado y se extiende hasta mediados del presente. En ella las teorías explicativas de mayor peso fueron primero el evolucionismo y posteriormente el difusionismo. 2) Una segunda etapa, durante los años sesenta y setenta de este siglo corresponde a la denominada Nueva Arqueología o Arqueología Procesual. Supone una ruptura con lo anterior e intenta adaptar los presupuestos teóricos y metodológicos de las
Ciencias Naturales a la Arqueología. El foco de atención se sitúa en los procesos de tipo general, alejándose de las teorías difusionistas como explicación del cambio cultural en favor de los procesos internos de cambio. 3) A partir de los años ochenta se inicia una nueva etapa que pretende superar la dependencia teórica y metodológica de las Ciencias Naturales y alejarse de la preocupación por la cuantificación. Sitúa su atención en aspectos simbólicos, ideológicos y sociales y enfatiza la pluralidad en la interpretación del pasado (Trigger, 1989; Hernando Gonzalo, 1992; Preucel, 1995).

Las tendencias recientes rompen con el mito de la «inocencia» del arqueólogo, al que se ha considerado científico objetivo totalmente al margen de la problemática que le rodeaba. En este sentido surge la disyuntiva entre la neutralidad o la politización. Podemos tomar como ejemplo la organización del Congreso Arqueológico Mundial. Si en 1986 en Inglaterra surgió la duda sobre si excluir a los arqueólogos de Sudáfrica como parte del boicot internacional (Rao, 1995), en el WAC-3 en India en 1994 se prohibió explícitamente abordar el tema de la mezquita de Ayodhya ante la posibilidad de conflictos de consecuencias graves (Álvarez-Sanchís, 1995; Colley, 1995). Lo que se está planteando ahora es cuáles son los límites de esa politización derivada de los propios planteamientos del WAC (Podgorny, 1996), lo que Preucel (1995: 160-162) denomina los «dilemas del postmodernismo».

Veremos cómo la mayoría de los autores que mencionaremos en el texto coincide en la necesidad de tomar conciencia de que la práctica arqueológica está determinada en mayor o menor medida por el contexto socio-político y en la importancia de una valoración del pasado que no parta de cero, sino que recupere materiales, gentes, historias no tenidas en cuenta antes. Se trata de una Arqueología activa en el presente, que recurre a los medios del momento (los «mass media», la información visual, etc.) para llevar a cabo los dos objetivos que expone como esenciales: concienciación y acción. Esto no puede desligarse de la importante renovación en los planteamientos museológicos que se ha producido en los últimos años en el ámbito francés (Hernández, 1994: 9) y en el anglo-americano cuyo eco empieza a sentirse también en nuestro país (Barril, 1995; Prats, 1994).

Los ejemplos escogidos son diferentes en el

T. P., 54, n. ${ }^{\circ} 1,1997$ 
tiempo y el espacio. Habría otros más referidos a Australia, América del Sur, Canadá o África, pero aquéllos pueden resultar suficientemente ilustrativos de fenómenos complejos y polimorfos como son el nacionalismo, el racismo o la xenofobia. A través de ellos podremos ver cómo el protagonismo europeo en la investigación histórica ha sido una constante tanto fuera de Europa donde hubo colonialismo, como dentro de Europa, donde se puede hablar de racismo, en el caso de Alemania o Noruega. Ese protagonismo no debemos verlo como un fenómeno del pasado. La perspectiva eurocentrista no se ha perdido a juzgar por la política cultural europea (Shore, 1993 y 1996).

\section{GRAN ZIMBABWE: UN EJEMPLO DE ARQUEOLOGÍA COLONIAL}

Gran Zimbabwe es un claro exponente de la relación entre la Arqueología y la política, en este caso, colonial y racista. En la práctica arqueológica en Zimbabwe se dieron cita las características que Trigger (1984: 361-363) señala como definidoras de las arqueologías coloniales. La Arqueología era practicada por población no nativa. Se enfatizaba el primitivismo de los colonizados como forma de justificar la conducta negativa hacia ellos. Las poblaciones colonizadas fueron objeto de mayor estudio por parte de la Etnografía (Olsen, 1986: 25). Se comparaban las poblaciones nativas contemporáneas con las fases más primitivas del desarrollo europeo. Se aceptaba un etnocentrismo o etno-nacionalismo en la visión de la evolución histórica. El primero mostraba una visión del pasado que glorificaba las acciones de los antepasados de un grupo dado como si fueran los artífices de los mayores logros de la cultura de toda la humanidad. El segundo ofrecía una interpretación del pasado tendente a la glorificación del «nosotros» europeo y a la infravaloración o la ignorancia de los otros pueblos, una forma de apropiación de otros pasados y otros logros culturales (Shnirelman, 1995: 3-5). La Prehistoria europea se percibía dinámica, en una línea de progreso frente a la Prehistoria de otros pueblos que se percibía estática, negándole toda posibilidad de avance.

Este cuadro se completa con las pinceladas del Ministro de Museos y Monumentos de Zim- babwe sobre la Arqueología en esos momentos (Pwiti, 1994: 340). Se utilizó como propaganda para transmitir un mensaje concreto a la población colonial a través de la censura en museos y bibliotecas con el fin de anular la posibilidad de un pasado nativo propio.

Las ruinas de Gran Zimbabwe ejemplifican habitualmente una arqueología racista. Dicho monumento, cercano a Fort Victoria, en el actual Zimbabwe, es una estructura de piedra muy sofisticada y con un acabado perfecto. Actualmente se interpreta como perteneciente al siglo XIII d.C., con su momento de máximo esplendor en el siglo XV d.C. y de origen autóctono (Renfrew y Bahn, 1991: 408; Huffman, 1987; Holl, 1996). Pero no siempre ha sido así; en el pasado se tejió en torno suyo toda una mitología sobre su construcción, atribuida a las más diversas gentes, excepto a los antepasados de la población contemporánea.

La primera descripción de las ruinas data de 1868. En 1890 Theodore Bent pone en relación las ruinas con la población fenicia. En esta misma época el exotismo y la fantasía se ven alimentados en la imaginación popular por novelas como las de Ridder Haggar (Posnansky, 1982: 347). A principios de este siglo Hall y Neal, dos aficionados, acrecientan el mito de los logros de las poblaciones foráneas en África: los fenicios o gentes venidas de Arabia Saudí, poblaciones invasoras o de mercaderes o de metalúrgicos, etc.. En una fecha tan tardía como 1971, el arqueólogo P.S. Garlake, Inspector de Monumentos de Rhodesia, es obligado a dimitir por no interpretar Zimbabwe de acuerdo con las ideas del gobierno del momento, de corte anti-autoctonista.

Posnansky (1982) sitúa las diferentes interpretaciones en un esquema evolutivo en el que aparecen, sin embargo, elementos discordantes frente a las teorías dominantes. Así, en los primeros momentos en que se imponen las teorías anti-autoctonistas, ya aparecen algunos defensores de las teorías autoctonistas. Y a la inversa (Posnansky, 1982: 347).

Otro investigador, Pwiti (1994), relaciona las diferentes interpretaciones sobre Zimbabwe con su contexto sociopolítico: una primera etapa se caracterizó por expediciones (1906; Gertrude Caton Thompson, 1931) destinadas a probar el origen foráneo que fracasaron. Una segunda etapa estaría caracterizada por la emergencia de los movimientos nacionalistas nativos posteriores a 
1960. Gran Zimbabwe se convierte en símbolo de un brillante pasado cultural indígena. La Arqueología es un tema de debate en el Parlamento de Zimbabwe y todavía sigue habiendo defensores del origen foráneo de la cultura. Es una fecha clave en la historia política y de la investigación que marca cambios de objetivos e intereses: unas mismas ruinas sirven para propósitos diferentes. El interés de los foráneos por ellas pasa al de los nativos que las convierten en un elemento de reivindicación histórica y nacional cargado de significado.

El objetivo principal es la recuperación del pasado principalmente mediante la investigación y la difusión (Pwiti, 1994). La investigación arqueológica se fomenta desde el convencimiento de que el conocimiento del pasado puede permitir planear el presente y el futuro. Lewis-Williams (1993: 49-50) recuerda que la Arqueología es una práctica política, de formación de conceptos. No es una ciencia libre de prejuicios sin impacto en la forma como la gente percibe sus propios valores y posiciones o las de otros. Las narrativas que producen los arqueólogos no deben hacerse a medida para materializar, justificar o explicar el presente; deben contarnos que el pasado pudo haber sido diferente. El pasado es un reto del presente. En relación con esto va cobrando cada vez más fuerza la idea de que el presente es el resultado de una de las posibles alternativas en el pasado, no la única. Ello supone en el contexto africano hacer frente a la «predestinación» o el «designio divino» que parecía envolver toda la política colonizadora.

La educación debe potenciar la enseñanza del propio pasado, frente a la tradición practicada hasta la independencia, en 1980, según la cual no había historia africana antes de la era colonial.

Otro vehículo de divulgación son los museos. Hay ya conciencia de la manipulación que ha habido del pasado local y de la necesidad de romper con falsas imágenes y de hacer públicos y accesibles los resultados de las investigaciones. Se considera de gran importancia para una nación que está surgiendo el derecho a conocer y tener un pasado de todos.

Está implícito en estos argumentos, por un lado, el peligro de caer en un extremo «afrocentrismo» (MacDonald et alii, 1995: 6), frente al colonialismo (McIntosh et alii, 1989: 77) y por otro lado, la idea de democratizar el conocimiento.

\section{LA ARQUEOLOGÍA DE LOS ESTADOS UNIDOS EN RELACIÓN CON LA POBLACIÓN NATIVA}

Se pueden identificar dos grandes líneas de actuación. La tónica en la práctica arqueológica estadounidense ha sido un desinterés por los indígenas, con distintos matices a lo largo del tiempo. Sin embargo, las últimas tendencias muestran que los nativos tienen un interés activo por la práctica arqueológica y al mismo tiempo que sus nuevas interpretaciones se convierten en elemento de resistencia frente a la historia oficial. Trigger (1980: 662) ha estudiado ese cambio. Expone cómo habían sido tratados como objetos de una forma peyorativa y sitúa la causa de la perduración de los estereotipos en la falta de contacto directo entre arqueólogos y población nativa.

La historia de la investigación en relación con los '«constructores de túmulos» de las cuencas del Ohio y el Missisipi (Renfrew y Bahn, 1991: 26-28) resulta muy expresiva de esa visión peyorativa. A pesar de que ha habido autores defensores del autoctonismo desde mediados del siglo pasado, la idea generalizada era que habían sido construidos por una raza mítica desaparecida. $\mathrm{La}$ razón según Trigger (1980: 665) es que no se creía que la población nativa pudiera haber creado culturas prehistóricas tan florecientes. Según otras hipotésis sus creadores serían poblaciones mexicanas desplazadas al sur o exterminadas por los antepasados de la población nativa actual, a los que se atribuía un carácter no civilizado. En esos momentos el registro arqueológico se empleó para justificar la guerra contra los indígenas y el derecho de apropiación de sus tierras (Fowler, 1987: 230).

Todo ese discurso no surge ex-nihilo. Tiene sus antecedentes en mitos religiosos y raciales muy anteriores. Los primeros están en relación con la conquista del Nuevo Mundo y con una visión del nativo como ser inferior al hombre civilizado, lo que daba a éste último el derecho a apropiarse de las tierras indias. Como dice Trigger (1980: 663): «América, metafóricamente, se convierte en una segunda Canaan que Dios ha alejado de sus habitantes originales para dársela al nuevo pueblo elegido». Los mitos raciales atribuyen a la población indígena la brutalidad, la belicosidad y la incapacidad de progreso.

Como muestras de esta segunda se pueden incluir tres estudios que reivindican una versión

T. P., 54, n. ${ }^{\circ} 1,1997$ 
nativa de los hechos históricos. McDonald et alii (1993) ponen en tela de juicio las rutas de huida de los nativos durante la «rebelión» cheyene de Fort Robinson en Nebraska durante el invierno de 1879 , dado el desacuerdo entre las versiones locales y militares y las de la tradición nativa oral. El resultado de la investigación apunta hacia una mayor coherencia de las rutas defendidas por la tradición oral.

Otros arqueólogos excavaron en el terreno delimitado como Monumento Nacional a la batalla de Custer, librada el 26 de Junio de 1876, entre el Séptimo de Caballería de los EE.UU. y los Sioux y los Cheyenes a orillas del río Little Bighorn en Montana. Recurrieron a tres fuentes principales de información, la arqueología, la historia y la tradición oral nativa concluyendo que la batalla sintetizó el choque de dos culturas, americananativa y euro-americana, con diferentes percepciones de la propiedad de la tierra, de los tratados y de las fronteras (Scott y Connor, 1986).

Finalmente según Rubertone (1989: 32-33) la Arqueología evidencia acciones de resistencia de los indios Narragansett que dominaban el área del actual Rhode Island, destinadas a preservar su independencia frente a la dominacion colonial y que la historia escrita no menciona.

En la investigación sobre los nativos de EE.UU. empiezan a vislumbrarse una serie de líneas de actuación, tendentes a recuperar el pasado que había estado sesgado por el racismo de quienes escribieron su historia. Por un lado se percibe el interés de algunos grupos, como los Pueblo de Zuni (Trigger, 1980: 673) en Nuevo Mexico, los Hopi o los Navajo (McGuire, 1992: 238), por trabajar como arqueólogos o contratarlos para estudiar su pasado. En parte también se pretende utilizar el pasado como justificación de sus respectivas reclamaciones territoriales dando prioridad al propio pasado frente al de los otros pueblos. Se sustituye así el eurocentrismo colonial por un nuevo «indiocentrismo».

Este activismo indígena que se asocia a reclamaciones de re-enterramiento o de repatriación de esqueletos y de control sobre su pasado (Ferguson, 1996; Rose et alii, 1996) no debe verse sólo como algo coyuntural ligado al desarrollo de las corrientes post-procesuales, sino que es una expresión más de toda una trayectoria reivindicativa de un grupo minoritario enfrentado a los mismos conflictos de marginación, segregación y pobreza que otras minorías dentro del multi- culturalismo de los Estados Unidos (McGuire, 1992: 240). La Arqueología se convierte así en instrumento político no inocente, en este caso de reversibilidad histórica: aquéllos cuyos antepasados fueron las «víctimas» de la historia en el pasado tratan ahora de legitimar sus propios proyectos y acciones (Shnirelman, 1995: 3). Por otro lado se acentúa la valoración de la Arqueología por su contribución al conocimiento de las culturas nativas desde los primeros tiempos y su desarrollo a lo largo de la Prehistoria. Así mismo se destaca el papel de la historia oral nativa respecto a las fuentes escritas, en su mayoría producto de la cultura euro-americana. Por último se cree necesario superar la definición de Historia como el estudio del hombre blanco y la de la Antropología como el de las gentes pretendidamente simples (Trigger, 1980: 673).

\section{LA ALEMANIA NAZI}

La singularidad del caso alemán radica en la utilización explícita de la Arqueología por el estado. Para entenderla hay que tener en cuenta que la Arqueología, como disciplina, se hallaba bastante desprestigiada, por lo que no debe extrañar que los arqueólogos se unieran al partido Nacional Socialista, que se mostraba ampliamente interesado por ella. Por otro lado es precisamente en el período comprendido entre 1935 y 1945 cuando se produce la institucionalización de la Arqueología. Este contexto científico se combinaba a nivel general con el trauma tras la derrota de 1918.

Como señala McCann (1990: 75) el pensamiento Nacional Socialista no es el creador de las ideas que maneja, pero sí su propagador. Entre ellas se encuentran las doctrinas de la desigualdad de las razas del filósofo del siglo XIX Gobineau. Por su parte Arnold (1990: 464) apunta, en el siglo XX, toda una serie de periódicos y publicaciones cuyo tema es la raza y la ingeniería genética y la teoría de los círculos culturales (kulturkreiss) que identificaba regiones geográficas con grupos étnicos basándose en la cultura material.

Uno de los principales objetivos de las interpretaciones arqueológicas era justificar la expansión territorial alemana (Arnold, 1990: 466). Para justificar las nuevas fronteras (conflictos con Dinamarca y Francia) se apela bien a la per- 
tenencia de los pueblos vecinos a la familia de lenguas germánicas, bien a una Europa de dominación germánica o nórdica en la Prehistoria, poniendo a su vez en cuestión la estructura de estados y la distribución de poder en la Europa del momento (Wiwjorra, 1996: 175). La expansión se justifica declarando territorio germánico todo aquél donde apareciera un artefacto de una cultura arqueológica atribuida a los germanos. Se manejaba un argumento difusionista: desde la cuna germánica sucesivas oleadas transmitirían la civilización a las culturas menos desarrolladas del sur. Se defiende una política de colonización agrícola emulando a los antepasados medievales (McCann, 1990: 84). La superioridad de la raza germánica justifica que sólo los auténticos germanos tengan derecho a su lebens raum («espacio vital»), aunque para ello recurran a la recolocación de pueblos como los eslavos o al exterminio de otros. El otro gran anhelo era rehabilitar la propia estima alemana tras la derrota de 1918. De acuerdo con estos planteamientos se atribuyen a la cultura alemana todos los logros tecnológicos y culturales occidentales.

Dentro de la práctica arqueológica diferentes autores comparten unas mismas ideas de fondo: la superioridad de una raza, la germánica, y los derechos que esto les da. Señalaremos solamente los nombres de algunos de los investigadores cuyos trabajos tuvieron una mayor repercusión.

Los deseos expansionistas nazis sobre Europa central y oriental tomaron a Gustav Kossinna (1852-1932) como soporte teórico. Lingüista y luego arqueólogo introdujo en la Arqueología la teoría de los círculos culturales y adoptó su modelo de difusión cultural: las influencias, las ideas y los modelos se transmiten por contacto de las gentes más avanzadas a las menos. En 1934 Alfred Rosemberg creó un «Departamento de Prehistoria» (Amt Rosemberg) dirigido por el arqueólogo Hans Reinerth, con el objetivo de reorientar la arqueología prehistórica hacia una prehistoria germánica y en 1935 Himmler la organización Ahnenerbe cuya actividad era excavar y restaurar las reliquias germánicas reales o imaginadas (Härke, 1991: 205).

Dentro de lo que podemos considerar acciones de propaganda recurrieron a todos los medios a su alcance para conseguir la difusión de sus ideas, su asimilación y una masiva participación de la población alemana en esa ideología: en definitiva una política de adoctrinamiento.
No se buscaba la objetividad, ni siquiera un respeto por el pasado, por lo que los prehistoriadores del partido distorsionaron los hechos y las SS destruyeron algunos yacimientos arqueológicos, como Biskupin en Polonia, que no encajaban dentro de sus presupuestos teóricos. En palabras del propio Himmler: se trataba de «proyectar en el débil y lejano pasado el cuadro de nuestra nación como la prevemos para el futuro. [...] [N]uestra enseñanza sobre los orígenes germánicos ha dependido durante siglos de la falsificación. Tenemos derecho a imponer un pasado nuestro en todo momento» (Arnold, 1992: 33).

Vemos aquí uno de los peligros que arrancan de tener el sentimiento de un «pasado falsificado»: una radicalización de posturas que lleva a enfatizar el pasado desde el polo opuesto al previo.

El partido nazi se apropió de datos prehistórićos y usó diseños simbólicos indoeuropeos y germánicos en los uniformes y condecoraciones. La esvástica, por ejemplo, se tomó de un símbolo solar indoeuropeo que aparece en decoraciones cerámicas neolíticas en Europa occidental y que continúa hasta época medieval (Arnold, 1992: 36).

Cabe mencionar la realización de películas arqueológicas por parte del prehistoriador Lothar Zotz y la publicación de periódicos de entre los cuales los más conocidos eran Die Kunde («El mensaje»), Germanen Erbe («Patrimonio germánico») y Ahenenerbe («Historia antigua»).

Se crearon museos al aire libre y se llevaron a cabo reconstrucciones de asentamientos neolíticos y de la Edad del Bronce en el lago Constanza (Arnold, 1992: 32). Toda la parafernalia se basaba en una conexión con el pasado remoto. Otra forma de actuación consistió en crear organizaciones amateur de carácter arqueológico, apelando al patriotismo. Las SS participaron activamente en las campañas arqueológicas.

No hay que olvidar tampoco la práctica de una auténtica «rapiña» histórica, artística y cultural (McCann, 1990: 83). La organización «Ahnenerbe» en el Este se apropió de objetos de procedencia germánica. En este sentido podemos recordar la visión algo deformada, pero en la que también hay algo de verdad, que las películas de Indiana Jones ofrecen sobre la actividad arqueológica nazi: la búsqueda de objetos de carácter místico y esotérico. El propio Himmler sentía gran pasión por el misticismo y lo oculto. 
Un elemento curioso es el papel que Hitler desempeñó en relación con la Arqueología y su uso. Hay una contradicción entre sus ideas y las defendidas por las SS respecto al pasado (Wiwjorra, 1996: 178-179). «[N]osotros todavía estábamos lanzando hachas de piedra en torno a fuegos al aire libre ... cuando Grecia y Roma habían alcanzado ya el más alto nivel cultural. Haríamos mejor manteniendo en silencio ese pasado» (Arnold, 1992: 36). Estos pensamientos no le impidieron, sin embargo, sancionar con su presencia en exhibiciones al aire libre, museos, etc. la glorificación del presente por medio del pasado.

La valoración crítica de esa etapa de la arqueología alemana es, en cierto modo, una «asignatura pendiente». Por un lado se trata de afrontar una realidad pasada, no cubrirla como algo que debe esconderse (Arnold, 1992: 37). Esto se está haciendo poco a poco a través de artículos y libros (Arnold, 1995). Por otro lado es también importante intentar comprender las elecciones que hicieron o evitaron los arqueólogos entre 1933 y 1945 (Arnold, 1992: 37). En cuanto a los investigadores, no todos actuaron igual. Algunos fueron oportunistas o auténticos creyentes; otros, la mayoría, aceptaron la apropiación de la arqueología prehistórica sin crítica alguna; y otros ejercieron una oposición abierta. Algunos fueron excluidos por criterios racistas: la «herencia judía» interrumpió la carrera del arqueólogo Gerhard Bersu (Arnold, 1992: 36-37; Wiwjorra, 1996: 177). La metodología no siempre se vió afectada por la ideología, y sólo se adaptó el vocabulario: la Edad del Bronce y la Edad del Hierro pre-romana pasaron a denominarse «período germánico temprano» (Arnold, 1990: 473).

Después de 1945 la situación de la Arqueología en Alemania no fue fácil. Por un lado la guerra, la emigración y el exterminio dejaron un número muy reducido de estudiantes. Por otro lado, éstos se enfrentaban a problemas de tipo psicológico: la humillación tras la derrota y la desprogramación metodológica. Como señala Arnold (1990: 475) tal vez ha habido hasta ahora falta de tiempo y de deseos de examinar las razones de la "prostitución de la arqueología germánica», por lo que llega el momento de tomar conciencia y actuar. Es necesario partir de la base de que la manipulación de la Arqueología y su instrumentalización como propaganda fue algo muy nega- tivo en el pasado y puede resultar un peligro presente y futuro.

Las medidas a tomar deben iniciarse conociendo cómo funciona la propaganda para evitar caer en la distorsión que crea. Para Arnold (1990: 475) «la esencia de la propaganda radica en la habilidad de manipular el lenguaje y los símbolos». El lenguaje puede enfatizar el mensaje racista subyacente, lo cual es algo familiar en la práctica de la arqueología colonial etc. En definitiva «una raza, nación o individuo puede ser difamado por términos con implicaciones negativas como «bárbaro», «subdesarrollado», «primitivo» (Arnold, 1990: 475).

En este sentido tiene gran importancia una labor de revisión de los textos arqueológicos y de los que aparecen en los diferentes medios de difusión: prensa, museos, etc. Es fundamental utilizar un lenguaje claro en todo momento para lograr la accesibilidad y comprensión de todos, evitando «la jerga profesional que tiende más a oscurecer que a revelar el significado» (Arnold, 1990: 475).

A la hora de valorar la propaganda nazi desde el presente debemos hacerlo desde una perspectiva dinámica. No fue un plan uniforme, monolítico, sino que se fue configurando con el paso del tiempo. También tuvo sus contradicciones, al entrar en juego conflictos entre intereses personales y estatales. Se dio una compleja combinación de ideologías previas, ideólogos del momento y de las propias circunstancias socio-económicas de la época.

Por último el problema que se está planteando hoy en torno a la práctica arqueológica en la Alemania Nazi no es tanto describir qué excesos se cometieron sino cómo pudieron producirse. El hiperrelativismo en «un ambiente intelectual donde lo 'real' se ve como una red de ideologías en competición, todas ellas igualmente verdaderas y todas ellas igualmente falsas» (Anthony, 1995: 85) puede llevar a nuevas versiones nacionalistas o etno-nacionalistas del pasado igualmente peligrosas. Este es el caso de la Sociedad para la Prehistoria y la Protohistoria en Alemania cuyo discurso en términos de raza, pueblo y germanos sostiene la convicción de una superioridad cultural racialmente determinada en los tiempos prehistóricos (Wiwjorra, 1996: 164188). La «arqueología profesional» no debería ignorar este tipo de discursos de «arqueología ficción» o «arqueología popular». 


\section{CONFLICTO ÉTNICO EN EL NORTE DE EUROPA: LA POBLACIÓN SAAMI}

Lo más impactante de este caso es el hecho de que haya un enfrentamiento con minorías étnicas (2) dentro del propio continente europeo.

El punto de partida es la existencia en la actualidad de dos grupos étnicos en Noruega: uno mayoritario, el noruego, y otro minoritario, el saami. La política gubernamental ha sido y es de carácter integracionista, por lo que se tiende a mostrar una sociedad homogénea, compuesta únicamente por la población noruega.

Este esquema se traslada al pasado, de manera que la única Prehistoria es la noruega, los saami se convierten en «pueblos sin pre-historia». De hecho se sabe muy poco de ellos. Hoy se concentran en la región más septentrional de Noruega. Sin embargo, se ha documentado su presencia en el pasado en zonas más al norte de Finlandia y Suecia donde no se ha tomado conciencia de la situación de conflicto (Zachrisson, 1994: 366).

Los estudios más recientes (Odner, 1985; Olsen, 1985; Aikio y Aikio, 1989; Zachrisson, 1994) parecen arrojar algo de luz sobre este grupo, más allá de las escasas referencias ofrecidas por la Etnografía. Las distintas investigaciones, tanto linguísticas como culturales, apuntan cada vez más al carácter «diferente» de la población saami que constituye un grupo étnico con entidad propia. Estas diferencias son, por un lado, de carácter cultural en cuanto a su modo de vida tradicional, nómada y basado en el pastoreo de renos, frente al de las poblaciones escandinavas, agrícolas y sedentarias. Hay también diferencias a nivel lingúístico, ya que su lengua original era ugro-finesa, no germánica, como las escandinavas. No hay datos reveladores, por el momento, de carácter genético.

En 1981 la población saami ha sido declarada comunidad indígena en la Convención Ilo 107, lo que le da derecho sobre un territorio y a mantener, recuperar y difundir su cultura, sus tradiciones y su historia. Lo que se estaba debatiendo no era solamente el carácter indígena de los saami,

(2) Tradicionalmente etnia hacía referencia a «un grupo de individuos que comparten un cierto número de rasgos en común -antropológicos, lingüísticos, político-históricos, etc.- la asociación de los cuales constituye una cultura». Sin embargo cada vez más la identidad étnica se define por oposición, «la concepción del propio grupo por parte de los miembros que lo configuran y de los otros como categoría de personas con identidades en oposición a otras categorías» (Ventura i Oller, 1994: 120, 123). sino toda una justificación territorial: definir a los indígenas como usuarios pero no poseedores de las tierras suponía mantener el punto de vista del conquistador, esto es que esas tierras no tenían dueños (Aikio y Aikio, 1989: 117).

El problema que se le plantea hoy a la Arqueología es que ha contribuido a mantener la imagen de homogeneidad que el estado pretendía y pretende difundir. La debilidad política y cultural de Noruega fomentó la necesidad de legitimarse como nación. Esta ideología nacionalista selecciona determinados elementos del pasado que se convierten en representativos del todo y en patrimonio nacional común (McGuire, 1992: 224). La Arqueología ha contribuido a este propósito en la búsqueda de ese pasado glorioso que se sitúa en la época vikinga (Olsen, 1986: 34).

La tónica en la práctica arqueológica ha sido el estudio de yacimientos noruegos, mientras que en el área de ocupación saami las investigaciones han sido escasas y orientadas principalmente a yacimientos de Prehistoria inicial (Paleolítico), dándose un total desinterés por la prehistoria reciente (Edad del Hierro). Este modo de actuación ha ido perfilando la imagen de una prehistoria única, la noruega, que se proyecta hacia el presente, a través de una historia única. Se crea de este modo una dialéctica en la que, al negar el pasado, se está negando el presente.

Ante esto ¿qué hacen los arqueólogos? Las tendencias, según su grado de compromiso, pueden resumirse en dos: «objetiva» y «activa». A lo largo de la historia de la Arqueología en Noruega ha tenido mayor peso la tendencia «objetiva», y todavía lo tiene hoy. La principal característica que la define es su intención de objetividad, de no politización. En esto podemos ver cierta semejanza con el caso de los nativos de Estados Unidos, estudiados desde distintos enfoques, pero siempre considerados como «objetos» desconectados de la población contemporánea. K. Odner (1985: 1), por ejemplo, dice explícitamente que quiere evitar entrar en la discusión política, dentro del contexto del debate sobre si los saami son población indígena o no.

La segunda tendencia, que hemos denominado arqueología «activa», es más bien un fenómeno reciente, en consonancia con las preocupaciones sociales de la práctica arqueológica dentro de la corriente general post-procesual. Así Aikio y Aikio (1989), por un lado, sacan a la luz el problema actual de la pérdida de referente histórico

T. P., 54, n. $^{\circ} 1,1997$ 
del grupo saami que no es noruego ni finlandés, que ha ido aculturándose progresivamente, y por otro, buscan su legado arqueológico que hasta ahora no se veía por ningún lado. En definitiva, ponen en relación la labor investigadora del arqueólogo con el contexto en el que se mueve.

Pasamos ahora a ver cuáles han sido los resultados de las investigaciones arqueológicas de las distintas tendencias. Dentro de la práctica arqueológica «objetiva» el trabajo de Odner (1985) está siendo revelador en muchos aspectos y supone una contribución esencial al conocimiento de los saami. Frente a la política uniformizadora estatal, su investigación apunta de una forma cada vez más clara hacia las diferencias lingüísticas y culturales desde un pasado lejano.

Desde la perspectiva de una arqueología «activa», Olsen (1986) introduce aspectos teóricos en relación con la problemática de los saami. En este sentido diferencia el discurso «politizado» del «despolitizado». El primero se vincula al surgimiento de movimientos reivindicativos de los derechos políticos de las minorías étnicas. Frente a éste está el discurso «despolitizado» que, en el fondo, no es tal pues en él también subyace un motivo político: promover una Noruega integrada en la dinámica europea, en la que no haya cabida para los pueblos denominados «primitivos». Olsen cuestiona si es comparable la vinculación de la Arqueología en el tema de la supresión étnica saami, con otros casos, como por ejemplo la arqueología nazi. Entraría aquí, por tanto, poner en tela de juicio si podemos hablar de consecuencias «duras» o «blandas» de la relación entre la Arqueología y la política. Su propuesta de actuación es rotunda: una actitud consciente y autocrítica. El presente no es una consecuencia inevitable del pasado, sino resultado de una de las diversas opciones que se dieron entonces.

Aikio y Aikio (1989) estudian un caso concreto, el destino de un grupo de pastores nómadas de renos saami desde 1800 hasta el presente. Estos saami se movieron desde el Lapland de las costas noruegas del Océano Ártico hacia los bosques interiores de coníferas de Finlandia y Suecia. Han sido víctimas de regulaciones fronterizas entre los países nórdicos y constituyen un ejemplo de cómo las poblaciones indígenas han sido afectadas por el proceso de colonización.

La solución de los conflictos del momento pasa por la adopción de una arqueología activa. Olsen (1986) y Aikio y Aikio (1989) recogen una serie de iniciativas que pueden considerarse una «toma de posición». En 1981 los arqueólogos noruegos se pusieron de acuerdo en definir como región cultural saami la provincia más septentrional de Noruega (Finmark) y algunas partes de otras y concebir a los saami de Noruega como población indígena según los acuerdos de la convención Ilo Número 107. Se basaron en hallazgos arqueológicos y otros tipos de fuentes de la época de colonización noruega de Finlandia que comenzó en la Edad Media. En esta reunión se puso de manifiesto la necesidad de revisar los estudios de los yacimientos arqueológicos. Ello supondría subvertir la visión etnocéntrica del conquistador. Así por ejemplo el trabajo del arqueólogo noruego Zachrisson (1994: 361) puso de manifiesto que asentamientos vikingos de la provincia de Härjedalen, en el sur de Suecia, interpretados tradicionalmente como indicadores del progreso de las conquistas vikingas, eran en realidad antiguos asentamientos saami.

Otro aspecto que se enfatiza es el interés de las poblaciones indígenas por investigar, descubrir e interpretar su propia historia, tradición y cultura. En este punto Zachrisson (1994: 366) indica la esperanza que se tiene en Suecia de alcanzar logros semejantes a los ya alcanzados en Noruega. En esta línea los estudiantes saami de la Universidad de Tromso, en Noruega, piden que no se realicen más excavaciones en territorio saami hasta que no puedan llevarlas a cabo arqueólogos saami. Opinan que desde su propia cultura pueden interpretar mejor los materiales arqueológicos (Aikio y Aikio, 1989: 128). Esta postura, sin embargo, constriñe la Arqueología al impedir que los investigadores no-indígenas estudien o interpreten el pasado nativo. En este caso como en el de la población indígena de los EE.UU. la Arqueología puede convertirse en un elemento de lucha política de un grupo minoritario y marginal donde a los conflictos de carácter étnico se unen los de clase: reivindicándose el derecho a la igualdad de oportunidades [y derechos] y a la diferencia.

\section{CONCLUSIONES}

Los arqueólogos se mueven entre dos polos: el ideal de un «pasado real» (Watson, 1986) y el real de la manipulación del pasado. La consciencia de las influencias ideológicas y valores que 
están pesando sobre ellos a la hora de actuar debería llevarles a contar el pasado con la mayor exactitud posible y a utilizar la información para responder a cuestiones de interés común sobre el comportamiento humano. Estas cuestiones deben estar continuamente sometidas al análisis crítico y a la revisión.

Teniendo en cuenta los ejemplos vistos anteriormente podemos concluir que la Historia es global, constituida por las historias interconectadas de «unos»y «otros». De ahí la importancia de recuperar cada fragmento antes no considerado, a cuya ignorancia ha contribuido la Arqueología. Dichos fragmentos son las historias de las minorías de todo tipo; son las historias de los «pueblos sin historia» (Wolf, 1982).

La puesta en práctica de esos presupuestos teóricos puede concretarse en dos parcelas fundamentalmente: la investigación y la difusión en sentido amplio -educación y medios de comunicación. En investigación Layton (1989: 17) subraya dos aspectos. El conocimiento de la población local puede ayudar a la interpretación del material arqueológico, con tal que se evite el extremo opuesto de desestimar las interpretaciones no-nativas. Además los arqueólogos deben cambiar su actitud hacia los restos materiales de las poblaciones indígenas, en ocasiones muy valiosos para éstas.

En el ámbito de la difusión parece claro el papel que la educación debe desempeñar. En algunos casos como en África, se pretende introducir por primera vez en las aulas la Arqueología y la Prehistoria (Barril, 1995: 66). En otros es más bien un proceso de cambio de enfoque, de ampliar los puntos de referencia. Así en Europa, al hablar de «identidad europea» se olvidan las contribuciones no-europeas de los residentes africanos, asiáticos, americanos u «otros» europeos (en términos de género, raza y clase) (Shore, 1993:79).

Ésta es una línea de actuación a desarrollar en España (Tovías, 1988) donde la enseñanza de un pasado diferente y plural es algo urgente hoy. ¿De esta nueva visión podrían beneficiarse no sólo la herencia musulmana, sino minorías actuales como los gitanos? Las escasísimas referencias a estudios sobre cultura material gitana proceden del Reino Unido y están vinculadas a proyectos de etnoarqueología (Parker Pearson, 1982). Sin embargo, como en el caso de otros grupos minoritarios (Rubertone, 1989; McGuire, 1992), la Arqueología permite contradecir la ver- sión textual, y hasta ahora única, de la historia de estas comunidades defendida por el grupo social dominante. Frente a los estereotipos de estatismo y falta de historia que se les atribuye como «primitivos actuales» en la «España comunitaria» se podrían constatar los muchos cambios producidos en su forma de vida (Calvo, 1990: 21) y en su cultura material donde los signos de aculturación son evidentes.

La divulgación empieza a enfatizar la necesidad de salir del marco estrictamente científico, cuidando las imágenes (Moser, 1992) y las publicaciones para evitar visiones deformadas que a menudo tienen más fuerza que las versiones científicas (MacDonald et alii, 1995: 83). No hay más que recordar la gran influencia que las novelas románticas, como Las minas del rey Salomón, ejercieron en el fortalecimiento de. la mitología en torno a Gran Zimbabwe a finales del siglo pasado (Posnansky, 1982: 347) o las películas como Indiana Jones o Star Gate en nuestros días. Se trata de adelantarse a lo que Kristiansen (1992: 28-29) denomina «arqueología ficticia y comercial».

Los museos también adquieren un protagonismo cada vez mayor por lo que cuidar la exposición de la cultura material y su interpretación constituye un nuevo reto. Lograr una representatividad plural (Barril, 1995: 170) de las poblaciones que hasta ahora no se han visto reflejadas en los museos no resulta fácil, pues se da la controversia entre la educación étnica y culturalmente específica y el multiculturalismo (Molyneaux, 1994: 7).

La importancia del pasado no radica sólo en su perpetuación, sino en que ayuda a definir nuestro lugar en un grupo social y una comunidad (Molyneaux, 1994: 9; Suffield, 1986: 8). El tipo de lenguaje que se utiliza es fundamental (Reid, 1991). Hay que evitar utilizar una jerga de iniciados (Arnold, 1990: 475), como instrumento de control del conocimiento que intente ocultar la información.

Se da una paradoja entre la demanda social de la Arqueología para recuperar el pasado y la manipulación que se ha hecho de él. La práctica arqueológica tiene dos caras: una positiva que busca servir a una justicia social en cada país y en relación con cada grupo humano, reconociendo los múltiples pasados que han configurado el presente. Otra ha negado u ocultado el pasado de naciones y gentes diversas, a menudo con crite- 
rios racistas o xenófobos, o lo ha tergiversado según los intereses del momento.

Hablar del pasado no debe hacernos perder la referencia del presente (Ruíz, 1994a, b). En concreto en el contexto europeo cabe señalar dos fenómenos recientes: uno es lo que se ha empezado a denominar «la arqueología de la guerra» (Chapman, 1994) y el «memoricidio» (Goytisolo, 1994) en relación con la situación desencadenada tras la guerra de Yugoslavia y toda una serie de acciones orientadas a destruir y borrar la presencia de los pueblos en determinados lugares. El otro es el proceso de «creación» de un pasado común europeo en torno al que surge la duda de si no se tratará del pasado de sólo unos pocos.

A nivel global se está produciendo un resurgimiento de los neo-nacionalismos y los renacimientos étnicos. Esto afecta a un número cada vez mayor de arqueólogos a sueldo de la administración pública que se ven presionados por la política y la práctica arqueológica (Kristiansen, 1992: 29; Kohl y Fawcet, 1995: 8). El problema que se plantea actualmente es la creación de una «identidad europea» supranacional (Shore, 1993: 792; Kohl y Fawcet, 1995: 17-18) o de nociones de cultura europea que se aproximan a discursos auténticamente racistas (Hall, 1991).

Teniendo en cuenta que conceptos como «nación» o «Europa» hacen referencia a entidades imaginadas, construidas mediante símbolos ¿qué tipo de Europa estamos creando? En relación con esto la Arqueología entra en juego al «desenterrar» elementos simbólicos, por ejemplo la esvástica o el sol de 16 puntas, símbolo de la antigua Macedonia, y en la actualidad emblema nacional de la «Ex-República Yugoslava de Macedonia» (Brown, 1994: 784; Kohl y Fawcet, 1995: 11).

En ese proceso de delimitación de quiénes están dentro y quiénes fuera de Europa (Dennell, 1996: 32; Mirza y Bungworth, 1995: 352) surgen contradicciones entre los datos arqueológicos y la realidad política. Se recurre por ejemplo a la «identidad céltica» como «identidad europea» (Dietler, 1994: 595-596). Sin embargo, se incluyen en la Unión Europea regiones del norte de Alemania y Escandinavia, en las que no se hablaron lenguas célticas ni existió la cultura material del complejo de La Tène y en cambio se excluyen amplias áreas de Europa oriental, claves en la definición de la cultura de La Tène (Dietler, 1994: 596). Lo que se pretende es dar autenticidad a la «comunidad imaginada» (Anderson, 1983) me- diante vínculos con la antigüedad céltica. Prueba de ello son las más de doce exposiciones sobre arqueología céltica realizadas desde 1980.

Como expone Hobsbawm (1992: 7) se están dando una serie de circunstancias favorecedoras del racismo y la xenofobia. Unas, ya bien formadas, como el proceso de desorientación y crisis. Otras, en proceso de creación, como la idea del «nosotros común frente al otro». Señala asimismo otro de los factores clave el miedo a la anomia, la desorientación. Ante lo fácilmente manipulables que resultan los datos arqueológicos el arqueólogo en su interpretación del pasado no puede ignorar todos estos fenómenos contemporáneos.

Los ejemplos vistos pueden dar la impresión de un cierto exotismo y a la vez de desconexión con la práctica arqueológica cotidiana en el contexto español. Sin embargo queda pendiente un análisis profundo y una autocrítica de la situación de la Arqueología en España y su relación con el racismo y la xenofobia. Aunque no podamos hablar de argumentos arqueológicos que apoyen o justifiquen la ocupación de territorios o que den validez a la versión histórica oficial frente a la historia de alguna minoría, esto no debe hacernos obviar toda una serie de interrogantes respecto a la práctica y a las motivaciones ideológicas que orientan la disciplina.

¿Qué implicaciones ha tenido una arqueología claramente nacionalista en la construcción de la identidad nacional, durante el regimen franquista, o de las identidades regionales con el surgimiento de la España de las autonomías? Partiendo de la relación existente entre la Arqueología y la ideología nacionalista desde sus comienzos (Díaz-Andreu, 1993; Díaz-Andreu y Mora, 1995) observamos la importancia que el pasado prehistórico ha tenido en los diversos discursos nacionalistas del siglo pasado, como en el andalucismo (Infante, 1984), el galleguismo (Maíz, 1983) y sigue teniendo en los nacionalismos vasco o catalán actuales. En dichos discursos nos encontramos con ideas próximas al racismo y la xenofobia (Hidalgo, 1996: 148-49). ¿Qué repercusiones puede tener una práctica arqueológica como la realizada en el País Vasco cuyo interés por la defensa de las diferencias raciales y étnicas ha sido y sigue siendo una constante avalada por los estudios antropológicos (Barandiarán, 1987)? ¿Qué posición deben tomar los arqueológos ante la difusión y utilización de argumentos arqueológicos por políticos como Xa- 
vier Arzallus (Hidalgo, 1996: 149)? ¿Cómo interpretar que sea en Cataluña donde se realicen un mayor número de estudios sobre genética de las poblaciones (Calafell y Bertranpetit, 1993)?

Afirmar que no puede haber una arqueología xenófoba en España puesto que no hay un «otro» excluido es algo que debería replantearse en el actual contexto pluricultural de nuestra sociedad. En la construcción histórica del origen de la nación el pasado andalusí ocupó un lugar liminal (Díaz-Andreu, 1996). ¿Hasta qué punto la Arqueología a través de las publicaciones y exposiciones sobre dicho pasado puede influir en la integración de la minoría islámica inmigrante o reforzar los estereotipos existentes (Andreu et alii, 1995)?

La reacción frente a la reconstrucción uniforme del pasado en la Arqueología ha supuesto la proliferación de historias de minorías de todo tipo. Esta reorientación teórica no debe ser una solución de compromiso que se acomode a tendencias pasajeras, ni conducirnos a un exceso de «corrección política» que acepte acríticamente estas reconstrucciones, evitando aplicar aquellos elementos de juicio que sin embargo nos hacen rechazar los abusos cometidos por la arqueología colonial o nazi en el pasado. Por el contrario debe permitirnos valorar críticamente qué aspectos de la Arqueología están siendo actualmente utilizados, distorsionados o manipulados en favor de determinados intereses y qué factores externos condicionan o favorecen tales acciones.

\section{AGRADECIMIENTOS}

A Gonzalo Ruíz Zapatero, Margarita DíazAndreu, Isabel Martínez Navarrete, Juan Vicent García, Antonio Uriarte González y María García Hernández por animarme a profundizar en este tema, por sus valiosas críticas y sugerencias bibliográficas y especialmente por la generosa atención que me han prestado durante la realización de este trabajo.

\section{BIBLIOGRAFÍA}

ADAm, H. (1984): «Racisme et categories du genre humain». L'homme, XXIV (2): 77-96.

Aikı, M. y Aikıo, P. (1989): «A chapter in the history of the colonization of samilands: the forced migration of Norwegian reinder sami to Finland in the 1880s».
En R. Layton (ed.): Conflict in the archaeology of living traditions. One World Archaeology, 8. Unwin Hyman. Londres: 32-45.

Álvarez SANCHís, J.R. (1995): «Ética y política. El envés del WAC». Complutum, 6: 397-398

ANDERSON, B. (1983): Imagined communities: reflections on the origin and spread of nationalism. Verso Press. Londres.

Andreu, M.; García, M.; Guimerá, C.; Masip, M.; RomeRo, J. y Rosell, M. (1995): "Les idees previes i l'ensenyament de les ciencies socials». L'Avenç, 188: 54-56.

AnThony, D.W. (1995): «Nazi and eco-feminism prehistories: ideology and empiricism in indo-european archaeology». En P. Kohl y C. Fawcet (eds.): Nationalism, politics and the practice of archaeology. Cambridge University Press. Cambridge: 82-96.

ARNOLD, B. (1990): «The past as propaganda: totalitarian archaeology in Nazi Germany». Antiquity, 64: 464478.

-. (1992) «Germany's nazi past: the past as propaganda. How Hitler's archaeologist distorted european prehistory to justify racist and terrritorial goals». Archaeology, 45 (4): 30-37.

ARnold, B. y HaSSMAN, H. (1995): «Archaeology in nazi Germany: the legacy of the Faustian Bargain». En P. Kohl y C. Fawcet (eds.): Nationalism, Politics and the practice of Archaeology. Cambridge University Press. Cambridge: 70-81.

BARANDIARÁN, I. (1987): «Los estudios sobre antropología prehistórica en el País Vasco». Veleia, 4: 1-50.

BARril Vicente, M. (1990): «El pasado: herencia, presentación e interpretación». Trabajos de Prehistoria, 52 (1): 165-175.

Brown, K.S. (1994): «Seein stars: Character and identity in the landscapes of modern Macedonia». Antiquity, 88: 784-796.

Calafell, F.; Bertranpetit, J. (1993): «The genetic history of the Iberian Peninsula: a simulation». Current Anthropology, 34: 735- 745.

Calvo Buezas, T. (1990): ¿España racista? Voces payas sobre los gitanos. Anthropos Editorial del Hombre. Barcelona.

Caton Thompson, G. (1931): The Zimbabwe Culture. Clarendon Press. Oxford.

Chapman, J. (1994): «Destruction of a common heritage: the archaeology of war in Croatia, Bosnia and Hercegovina». Antiquity, 88: 120-26.

Colley, S. (1995): «What happened at WAC-3». Antiquity, 69: 15-18

Dennell, R. (1996): «Nationalism and identity in Britain and Europe». En J.A. Atkinson, I. Banks y Y. O’Sullivan (eds.): Nationalism and Archaeology. Cruithne Press. Glasgow: 22-34.

Díaz-Andreu, M. (1994): «The past in the present: The search for roots in cultural nationalism. The Spanish

T. P., 54, n. $^{\circ} 1,1997$ 
case». En J.G. Beramendi; R. Maíz y X. Núñez (eds.): Nationalism in Europe past and present: actas do Congreso Internacional os Nacionalismos en Europa pasado e presente (Santiago de Compostela, 1993). Universidade Santiago de Compostela: 199218.

- (1996): «Islamic archaeology and the origin of the spanish nation». En M. Díaz-Andreu y T. Champion (eds.): "Archaeology and nationalism in Europe. UCL Press. Londres: 68-89.

DíAz-Andreu, M. y Mora, G. (1995): «Arqueología y política: el desarrollo de la arqueología española en su contexto histórico». Trabajos de Prehistoria, 52 (1): $25-38$.

DIETLER, M. (1994) «'Our ancestors the gauls': archaeology, ethnic nationalism, and the manipulation of celtic identity in modern Europe». American Anthropologist, 96 (3): 584-605.

FERGuSON, T.J. (1996): «Native americans and the practice of archaeology». Annual Review of Anthropology, 25: 63-79.

FowLER, D.D. (1987): «Uses of the past: archaeology in the service of The State». American Antiquity, 52 (2): 229-248.

GARLAKE, P.S. (1978): The kingdoms of Africa. Elsevier Phaidon. Londres.

Goytisolo, J. (1994): «La guerra en el Mediterráneo». El viejo topo, 78: 37-41.

HALL, M. (1984): «The burden of tribalism: the social context of Southern African Iron Age studies». American Antiquity, 49 (3): 455-467.

HaLl, S. (1991): «Europe's other self». Marxism Today. August 18-19.

HÄrke, H. (1991): «All quiet on the western front? Paradigms, methods and approaches in West German archaeology». En I. Hodder (ed.): Archaeological theory in Europe. The last three decades. Routledge. Londres: 187-222.

Hernando Gonzalo, A. (1992): «Enfoques teóricos en arqueología». Spal, 1: 11- 35.

Hidalgo Tuñón, A. (1996): «Xenofobia». En F. Blázquez-Ruíz (dir.): Diez palabras sobre racismo y xenofobia. EVD. Pamplona: 93-165.

Hoвsваwм, E.J. (1992): «Ethnicity and nationalism in Europe today». Anthropology today, 8 (1): 3-8.

Holl, F.C. (1996): «Book review: A diachronic analysis of the architecture of the hill complex at Great Zimbabwe by Kundishora T. Chipunza 1994». African Archaeological Review, 13 (1): 77-85.

HuFFMAN, T.N. (1987): Symbols in stone: unravelling the mystery of Great Zimbabwe. Johanesburgo.

Infante, B. (1984): Fundamentos de Andalucía. Fundación Blas Infante. Sevilla.

JONES, S. (1996): «Discourses of identity in the interpretation of the past». En P. Graves-Brown, S. Jones y C. Gamble (eds.): Cultural identity and Archaeology.
The construction of European Communities. Routledge. Londres: 62-80.

KoHL, Ph.L. y Fawcet, C. (1995): «Archaeology in the service of the state: theoretical considerations». En $\mathrm{Ph} . \mathrm{L}$. Kohl y C. Fawcet (eds.): Nationalism politics and the practice of archaeology. Cambridge University Press. Cambridge: 3-18.

KRISTIANSEN, K. (1990): «National archaeology in the age of european integration». Antiquity, 64: 825-8.

- (1992) «The strengh of the past and its great myth: an essay on the use of the past». Journal of European Archaeology, 1 :3-32.

LAYTON, R. (1989): «Introduction who needs the past?». En R. Layton (ed.): Who needs the past? Indigenous values and archaeology. One World Archaeology, 5. Unwin Hyman. Londres: 1-20.

Lewis-Williams, J.D. (1993): «Southern African archaeology in the 1990s». Southern African Archaeological Bulletin, 48: 45-50.

MacDonald, D.; Hung, F.Y.C. y CRawford, H. (1995): «Prehistory as propaganda». Papers from the Institute of Archaeology, 6:1-10.

MAíz, R. (1984): Alfredo Brañas. Galaxia. Vigo.

MCCAN, B. (1990): "Volk und germanentun: the representation of the past in nazi germany». En P. Gathercole y D. Lowenthal (eds.): The politics of the past. One World Archaeology, 4. Unwin Hyman. Londres: 74-91.

McDonald, I.D.; Simmerman, J.; McDonald, A.L.; TAll Bull, W. y Rising Sun, T. (1986): «La rebelión de los cheyenes del norte (1879): el uso de la historia oral y la arqueología como instrumento de resistencia». Taller de Historia, 1: 37-44. Valencia.

McGuire, R.H. (1992): «Critical archaeology-Archaeology and the vanishing american». En R.H. McGuire (ed.): A marxist archaeology. Academic Press. California: 213-247.

McIintosh, R.; McIntosh, S.K. y Togola, T. (1989): «People without history». Archaeology, 42 (1): 74$80 ; 107$.

MirzA, M.N. y DungorTh, D.B. (1995): «The potential misuse of genetic analyses and the social construction of 'race' and 'ethnicity'». Oxford Journal of Archaeology, 14 (3): 345-354.

MolineauX, B.L.(1994): «Introduction the presented past». En P. Stone y B.L. Molineaux (eds.): The presented past, Heritage, museums and education. One World Archaeology, 25. Routledge. Londres: 1-13.

Moser, S. (1992): «The visual language of Archaeology, a case study of the Neanderthales». Antiquity, 66: 831-44.

ODNER, K. (1985): «Saamis (Laaps), Finns and Scandinavians in history and prehistory. Ethnic origins and ethnic processes in Fenno-Scandinavia». Norwegian Archaeological Review, 18 (1-2): 1-12.

Olsen, B. (1985): «Comments on Saamis, Finns and

T. P., 54, n. ${ }^{\circ} 1,1997$ 
Scandinavians in history and prehistory». Norwegian Archaeological Review, 18 (1-2): 13-18.

- (1986): «Norwegian archaeology and the people without (pre)-history: or how to create the myth of uniform past». Archaeological Review from Cambridge, 5 (1): 25-42.

Podgorny, I. (1996): «El Tercer Congreso Arqueológico Mundial en Nueva Delhi y los límites de la ingenuidad postmoderna». Relaciones de la Sociedad Argentina de Antropología, 21: 1-13.

PosnAnsky, M. (1982): «African come of age». World Archaeology, 13 (3): 345-358.

Prats, C. (1994): «Finalidad y proyección social de los museos, desde la perspectiva de la comunicación científica». Arqrítica, 7: 12-13.

Preucel, R.W. (1995): «The postprocessual condition». Journal of Archaeological Research, 3 (2): 147-175.

Pwiti, G. (1994): «Prehistory, archaeology and education in Zimbabwe». En P.G. Stone (eds.): The presented past. Heritage, museums and education. One World Achaeology, 25. Unwin Hyman. Londres: 338-348.

RAO, N. (1995): «Politics and the World Archaeological Congress [-3]».Trabajos de Prehistoria, 52 (1): 5-11.

REID, J.J. (1991): «Editor's corner: on the language of archaeology». American Antiquity, 56 (3): 387-388.

Renfrew, C. y BAHN, P. (1991): Archaeology, Theories, Methods and Practices. Thames and Hudson. Londres.

Rose, J.C.; Green, T.J. y Green, V.D. (1996): «NAGPRA IS FOREVER: Osteology and Repatriation of Skeletons». Annual Review of Anthropology, 25: 81-103.

RUBERTONE, P.E. (1989): «Archaeology, colonialism and the 17th century native America: towards an alternative interpretation». En R. Layton (ed.): The conflict in the archaeology of living traditions. One World Archaeology, 8. Unwin Hyman. Londres: 32-45.

Ruiz Zapatero, G. (1994a): «Arqueología y discurso político: el pasado como arma». Arqrítica, 8: 12-13.

- (1994b): «¿Por una Europa arqueológica unida?». Trabajos de Prehistoria, 51 (2): 191-193.

SCOTT, D.D. y ConNor, M.A.(1986): «Post-mortem at the little Bighorn». Natural History, 6: 46-55.

Shnirelman, V.A. (1995): «Alternative prehistory». Journal of European Prehistory, 3 (2): 1-20.

SHORE, C. (1993): «Inventing the 'peoples Europe'. Critical approach to European Community 'cultural policy'». Man (n.s.), 28: 779-800.
- (1996): «Imagining the new Europe: identity and heritage in European Community discourse». En P. Graves- Brown, S. Jones y C. Gamble (eds.): Cultural identity and archaeology. The construction of $E u$ ropean Communities. Routledge. Londres: 96-125.

SHORE, C. y BLACK, A. (1992): «The European Communities and the construction of Europe». Anthropology Today, 8 (3): 10-11.

SLAPSAAK, B. (1993): «Archaeology and the contemporary myths of the past». Journal of European Archaeology, 1 (2): 191-195.

STONE, P.G. (1989): «Interpretations and uses of the past in modern Britain and Europe. Why are people interested in the past? Do the experts know or care? A plea for further study». En R. Layton (ed.): Who needs the past? Indigenous values and archaeology. One World Archaeology, 5. Unwin Hyman. Londres: 195-206.

SUFFIELD, D. (1986): «Multicultural perceptions of the past by children and their parents in relation to teaching within schools». The World Archaeological Congress [-1]. Allen y Unwin. Southampton: 1-26.

TovíAs, S. (1988): «Pluralisme cultural, un repte per a l'escola». L'Avenç, 198: 68-69.

Trigger, B.G. (1980): «Archaeology and the image of the indian». American Antiquity, 45: 662-676.

- (1984) «Alternative archaeologies: nationalism, colonialism, imperialism». Man, XIX (3): 355-370.

- (1989) A history of archaeological thought. Cambridge University Press. Cambridge.

VV.AA. (1996): «The future of african archaeology». African Archaeological Review, 13 (1): 5-35.

Watson, P.J. (1986): «Archaeological interpretation, 1985». En D.J. Meltzer, D.D. Fowler y J.A. Sabloff (eds.):AmericanArchaeology Past and Future. Smithsonian Institute Press. Washington: 439- 457.

WiWJORRA, I. (1996): «German archaeology and it's relation to nationalism and racism». En M. Díaz-Andreu y T. Champion (eds.): Nationalism and archaeology in Europe. UCL Press. Londres: 64-188.

Wolf, E.R. (1982): Europe and the people without history. University of California Press. Berkeley y Los Angeles California.

ZACHRISSON, J. (1994): «Archaeology and politics: saami prehistory and history in central Scandinavia». Journal of European Archaeology, 2 (2): 361-368. 